\title{
LA DIFÍCIL TAREA DE LA INTERCULTURALIDAD DESDE LA DIDÁCTICA DE LAS CIENCIAS SOCIALES. ANÁLISIS COMPARATIVO DE LOS PROGRAMAS DE ARGENTINA, COLOMBIA Y CHILE
}

\author{
The Difficult Task of Interculturality from the Social Sciences Teaching. \\ Comparative Analysis of the Programs of Argentina, Colombia and Chile
}

\author{
Jesús Marolla ${ }^{1}$ \\ jesusmarolla@gmail.com \\ Universidad Metropolitana de Ciencias de la Educación (UMCE). Chile
}

Fecha de recepción: 01/03/2019

Fecha de aceptación: 04/07/2019

Resumen: El siguiente artículo es un estudio comparativo del currículo que se utilizan en la actualidad en los países de Argentina, Colombia y Chile en torno al trabajo de la interculturalidad. En el escrito se analiza y reflexiona, desde la literacidad crítica el tratamiento que se realiza a los textos, las actividades y las propuestas de enseñanza y de aprendizaje curriculares considerando las perspectivas teóricas sobre el multiculturalismo y la interculturalidad crítica definidas por Walsh (2012), Quijano (2000) y Tubino (2005). Se plantean las presencias y las ausencias en torno a los migrantes, las etnias indígenas y los afrodescendientes que forman parte de los relatos que se incluyen en los currículos, así como los roles y los discursos que se transmiten sobre sus acciones y participación en la sociedad. Los objetivos que se persiguen son reflexionar sobre la presencia y/o ausencia de las etnias y los grupos afrodescendientes en los currículos de dichos países y analizar el rol que se le asigna a dichos grupos en los documentos que forman parte del estudio. El presente trabajo forma parte de una investigación más amplia que se encarga de indagar sobre

1 Orcid: <https://orcid.org/0000-0001-6215-0010>. Investigador de la Universidad Metropolitana de Ciencias de la Educación (UMCE). Doctor en Educación en Didáctica de las Ciencias Sociales, Universidad Autónoma de Barcelona (UAB). Master en Investigación en Educación en Didáctica de las Ciencias Sociales, Universidad Autónoma de Barcelona (UAB), Profesor de Historia, Geografía y Educación Cívica, Universidad Metropolitana de Ciencias de la Educación (UMCE). 
las concepciones de los y las profesores de historia y ciencias sociales en establecimientos con presencia de estudiantes migrantes. Desde la didáctica de las ciencias sociales se reflexiona sobre los procesos y discursos sobre la inclusión, la migración, las etnias, los afrodescendientes y sus roles en la construcción de la historia.

Palabras clave: interculturalidad; multiculturalidad; currículo; inclusión; discriminación.

Abstract: The following article is a comparative study of the curriculum that is currently used in the countries of Argentina, Colombia and Chile about the work of interculturality. The paper analyzes and reflects, from critical media literacy, the treatment of texts, activities and curricular teaching and learning proposals considering the theoretical perspectives on multiculturalism and critical interculturality defined by Walsh (2012), Quijano (2000) and Tubino (2005). Presences and absences migrants, indigenous ethnicities and Afro-descendants that are part of the stories included in the curricula are presented, as well as the roles and speeches that are transmitted about their actions and participation in society. The objectives are to reflect on the presence and / or absence of ethnicities and Afro-descendant groups in the curricula of these countries and analyze the role assigned to these groups in the documents that are part of the study. The present work is part of a broader investigation that is in charge of investigating the conceptions of the teachers of history and social sciences in establishments with the presence of migrant students. From the didactics of the social sciences, we reflect on the processes and discourses on inclusion, migration, ethnicities, Afro-descendants and their roles in the construction of history.

Keywords: Interculturality; multiculturalism; curriculum; inclusión; discrimination.

SUMARIO: 1. Marco Teórico. 2. El currículo de Chile. Presencias y ausencia de la interculturalidad. 3. El currículo de Argentina. Programas de ciencias sociales y el de Formación Ética y Ciudadana. 4. El currículo de Colombia: una propuesta desde la interculturalidad. 5. Conclusiones. 6. Referencias bibliográficas.

\section{MARCO TEÓRICO}

Para comprender el análisis realizado en el escrito, me posiciono y entiendo, desde la Didáctica, el fenómeno de la interculturalidad como un posicionamiento y un proceso que cuestiona las luchas hegemónicas que se han dado en la sociedad (Hall, 1997). No se puede comprender el proceso de la interculturalidad fuera de las redes de poder, las subjetividades y las políticas de identidad y los contextos en que se han performado.

Desde la enseñanza de la historia y las ciencias sociales, los conceptos de ciudadanía e identidad han estado ligados a la formación de los estados-nación y la transmisión de una simbología nacional (Miralles y Gómez, 2017; Barton, 2010). El racismo ha sido, tradicional e históricamente, un fenómeno estructural que opera a través de diferentes concepciones y prácticas que ha establecido jerarquías en torno a las poblaciones culturales (Castillo, 2011). 


\section{a. La escuela}

Castillo (2011) dice que la escuela ha sido y continúa siendo una de las estructuras e instituciones donde no solo se han dado las interacciones entre las distintas culturas, sino que es el espacio donde interactúan las hegemonías y las instancias de poder para producir y reproducir las categorías y las jerarquías raciales. La escuela ha contribuido a la generación de prácticas y saberes que han posicionado a un «hombre occidental y blanco» por sobre los aborígenes, mestizos y afrodescendientes.

La educación ha cumplido la función de producir y reproducir procesos que han permitido la transmisión de conocimientos que persiguen la conformación de identidades, roles y una cultura especifica en la sociedad. De esa manera, la escuela funciona como un ente regulador de las jerarquías sociales y epistémicas a través de los contenidos, las prácticas y los discursos que se transmiten. Desde las políticas de reconocimiento (Castillo y Rojas, 2007), la escuela funciona como una estructura que persigue la legitimación de los esquemas de subordinación que se han instaurado en los proyectos de modernidad-colonialidad.

Las perspectivas raciales, de esa manera, son parte de los "contenidos» que se socializan y se transmiten a través del currículo y los materiales (Apple, 1991). Los contenidos relacionados a la visión inferiorizada de lo negro, lo africano, lo aborigen y lo mestizo forma parte de las prácticas y los discursos que se producen y reproducen en tales materiales de manera normalizada. Quijano (2000) al respecto, define lo anterior como "colonialidad del poder», donde a través de la raza se han construido escalas de identidades sociales con el blanco europeo en las jerarquías superiores, quedando los aborígenes y los negros en los últimos peldaños.

\section{b. ¿Proyectos multiculturales o interculturales?}

Walsh (2004) dice que la multiculturalidad, en efecto, es parte de un proyecto político que se basa en el reconocimiento, la inclusión y la incorporación de la diversidad cultural no con fines de transformación, sino para mantener el statu quo. Para el caso actual, el statu quo viene a ser la ideología neoliberal. En efecto, dentro de distintos países se están llevando a cabo procesos de reconocimiento étnicos. La diversidad, en este sentido, es asumida como parte de las lógicas de la cultura dominante. Quijano (2000) y Castillo y Rojas (2007) destacan el énfasis entregado al multiculturalismo como expresión de una política de representación del capitalismo global.

Walsh (2011) afirma que existen tres perspectivas desde las cuales se pueden comprender los procesos y los fenómenos de la multiculturalidad y la interculturalidad: la relacional, la funcional y la crítica. La perspectiva relacional, dice referencia al contacto entre las culturas. Tal contacto podría darse en condiciones de igualdad 
o desigualdad, de ahí que se asuma que la interculturalidad sea un proceso que ha existido históricamente en la sociedad (Walsh, 2011, p. 101). Tal perspectiva, suele minimizar los conflictos de poder y dominación que se han dado entre las culturas. Por aquello se limita la interculturalidad a las relaciones individuales por sobre las estructurales, naturalizando de esa manera los procesos de racismo y de discriminación.

La perspectiva funcional, se basa en los planteamientos de Tubino (2005). Tal perspectiva comprende las medidas tomadas por parte de los Estados, los gobiernos y otros organismos por el reconocimiento social de las etnias, los aborígenes, los afrodescendientes y los migrantes. Se propone el dialogo, la convivencia, la tolerancia y la inclusión, formulando una interculturalidad "funcional» al sistema. No existe cuestionamiento a las lógicas del modelo económico ni político existente (Walsh, 2011, p. 101). En efecto, tal perspectiva se enmarca en los procesos actuales del capitalismo global, donde a pesar de que se reconocen las diferencias, estas se vacían de su significado y se vuelven funcionales al orden capitalista y colonial. Castillo y Rojas (2007) dicen que, en este contexto, las políticas estatales promueven las reivindicaciones de las etnias y los grupos afrodescendientes, siempre que sean dentro de la matriz dominante, asistiendo a «novedosas formas de legitimación de una versión hegemónica de multiculturalismo» (Castillo y Rojas, 2007, p. 18).

Desde otra vertiente, la perspectiva crítica de la interculturalidad se posiciona desde el problema estructural colonial-racial. Se reconoce que se han construido jerarquías racializadas. Walsh (2011) dice que la interculturalidad debería ser una herramienta que aporte al proceso de subversión y transformación de las estructuras coloniales, de ahí que se base en las lógicas poscoloniales para comprender la problemática (Spivak, 2012). Se aspira, por tanto, a cambiar las estructuras, las condiciones de inferiorización, la racialización y los dispositivos de poder bajo los cuales se han reproducido las estructuras de segregación inter-culturas (Spivak, 2012; Walsh, 2011). Para conseguir la transformación social, por tanto, se debe trabajar, reflexionar y criticar los proyectos políticos y estructuras interculturales desde las diferencias ontológicas, políticas, epistémicas y económicas (Quijano, 2000).

\section{c. Currículum}

Existen numerosos estudios sobre el currículo y los manuales escolares que reflexionan en torno a la interculturalidad, entre los que se podrían mencionar: Soler (2008) y Mena (2009) en Colombia, Granda (2000) en Ecuador, Zárate (2011) en Perú y Balsas (2011) y Romero (2010) en Argentina. En general, concluyen que la escuela y la enseñanza de la historia y las ciencias sociales se han encargado de producir y reproducir las estructuras raciales que han formado el racismo epistémico, marginando los saberes y reproduciendo los estereotipos y los prejuicios en torno a las poblaciones de origen africano como a las aborígenes. 
Quijano (2014) afirma que se deben someter a reflexión desde una lógica decolonial que pretenda acabar con el racismo epistémico o como le llama, la «colonialidad del saber». Así, propone la deconstrucción de la historia que se ha formado por los dispositivos de poder (Foucault, 2001). Tal proceso, desde lógicas decoloniales, implica el cuestionamiento y reelaboración de los programas y el currículo desde perspectivas críticas (Spivak, 2012). Por ejemplo, Mena (2009), en sus estudios, afirma que los contenidos de algunos currículos escolares de ciencias sociales, en general, dan cuenta de una historia sobre los afrodescendientes fragmentada. Las ciencias sociales, para la autora, se basa en relatos etno y eurocéntricos, los cuales reafirman no solo los estereotipos y los prejuicios, sino que las lógicas y las jerarquías coloniales e históricas en torno a los grupos étnicos, así como hacia los afrodescendientes.

Foucault (2001) da algunas pistas para analizar los procesos de interculturalidad. El poder no es solo una imposición de la voluntad e intereses de unos pocos sobre otros. El poder usa tecnologías y lógicas que colonizan, modifican, transforman e imponen distintos mecanismos que pretenden la dominación global (Foucault, 2001 , p. 32). Los procesos de jerarquía racial se podrían explicar como la organización de las estructuras y los mecanismos del poder en función de la estratificación social y global (Bourdieu, 1981).

En cuanto al trabajo con el currículo y los libros de texto, Miralles y Gómez (2017) dicen que son un «artefacto cultural» clave en los procesos de comprensión de las propuestas que provienen de las estructuras del poder (Miralles y Gómez, 2017, p. 11), ya que, desde tales espacios, se transmiten las ideas de identidad, cultura, política, entre otras. Los materiales, en general, no destacan la diversidad ni la otredad (Marolla, 2019; Marolla y Pagès, 2015). Se han presentado a los aborígenes y los afrodescendientes desde estereotipos que los asocian a seres "exóticos», "conflictivos» y/o «salvajes» (Soler, 2008). En esta construcción, se destacan acciones «anecdóticas» por sobre su participación en los «grandes procesos» donde destacan el hombre occidental, europeo y blanco. Se ha invisibilizado a los grupos étnicos y afrodescendientes de la construcción de la historia. La visibilización es bajo las estructuras "coloniales del poder» (Quijano, 2000), donde los roles y los lugares que ocupan las etnias aborígenes y los afrodescendientes dentro de la estructura global son impuestas por las lógicas del capitalismo mundial, la herencia colonial y las jerarquías raciales históricas de la larga duración (Fontana, 2002).

\section{d. ¿Qué se entiende por Literacidad crítica? La perspectiva para analizar los textos}

Ortega y Pagès (2017) comentan que por literacidad crítica entienden la «gestión de la ideología de los discursos históricos, al leer y escribir» o «los conocimientos, habilidades y actitudes y valores derivados del uso generalizados, histórico, individual y social del código escrito, visual, sonoro o audiovisual» (Cassany, 2006, 
p. 89; Ortega y Pagès, 2017, p. 102). Tosar y Santisteban (2016) afirman que a través de la Literacidad Crítica (LC) se puede analizar los currículos con una mirada crítica, lo cual colabora en establecer posiciones frente a temas controvertidos. Lo fundamental, como dice Santisteban (2015), es que desde la LC se den las herramientas a los estudiantes para que puedan leer las líneas (comprensión literal), leer entre líneas (comprensión inferencial) y leer tras las líneas (comprensión de la ideología) (Santisteban, 2015, p. 384).

Para el análisis del currículum, se considera lo que afirman Ortega y Pagès (2017), quienes dicen que al analizar los materiales utilizando las metodologías de la LC, se ahonda en la deconstrucción del relato social del presente, del pasado y del futuro. De esa manera, se puede reflexionar sobre las creencias, las representaciones y las prácticas sociales que se han formado.

\title{
e. Estrategias de análisis desde la Literacidad Crítica
}

No se puede desconocer, como afirman Zárate (2010) y Miralles y Gómez (2017) que los y las docentes se basan, para la planificación de sus clases, tanto en los libros de texto, como en el currículo prestablecido. Es necesario reconocer, de esta manera, lo que plantea Zárate (2010), quien afirma que los materiales responden, principalmente, a productos histórico-culturales, permeados por relaciones de poder, identidades y prácticas sociales.

Valle (2009) dice que las ideologías se transmiten a través de las lecturas y, en este caso, los materiales. Consideramos los aportes de la literacidad crítica, según los aportes de McLaughlin y DeVoogd (2004), ya que: a) se centra en los problemas y su complejidad; b) reflexiona sobre los usos del poder y promueve la reflexión y la transformación; c) examina diferentes perspectivas, contextos y puntos de vistas. Para el análisis y la reflexión, me posiciono bajo las preguntas que plantea Tosar (2018):

\author{
¿Quién está representado? \\ ¿Qué voces faltan? \\ ¿Quién se beneficia de esto? \\ ¿Qué medidas podrías tomar en base al texto?
}

Fuente: Tosar (2018, p. 7).

Tosar (2018) dice que, en base a las preguntas anteriores, se pueden comprender los materiales más que como una lectura y escritura, como una práctica social educativa para aprender a interpretar los contenidos de los artefactos textuales, 
analizar las ideologías de los discursos desde diferentes puntos de vista, reflexionar sobre los contextos, los silencios y considerar los posibles efectos de los mensajes. Finalmente, tales preguntas buscan promover una actitud de reflexión y acción en torno a las relaciones de poder que amagan los discursos, donde la LC «[...] es aprender a leer el mundo para denunciar si un discurso reproduce o resiste las desigualdades» (Tosar, 2018, p. 5).

\section{EL CURRÍ́culo de CHILE. PRESENCIAS Y AUSENCIA DE LA INTERCULTURALIDAD}

El programa de estudio de historia y ciencias sociales, en sus bases plantea el reconocimiento a la diversidad como uno de los ejes primordiales para la educación primaria. En efecto, se reconoce que: «el docente debe tomar en cuenta la diversidad entre los estudiantes en términos culturales, sociales, étnicos, religiosos y respeto de las diferencias entre hombres y mujeres, estilos y ritmos de aprendizaje, y niveles de conocimiento". (MINEDUC, 2013a, p. 16). En efecto, las bases curriculares del Ministerio afirman que la educación en Chile debería contribuir al desarrollo de la propia identidad, reconociendo que «cada ser humano es único y que todas las personas son diferentes» (MINEDUC, 2013a, pp. 30-33).

Las bases, en este sentido, proponen que los estudiantes puedan desarrollar habilidades de empatía y pertenencia a una comunidad, como así de respeto a la diversidad del país. No obstante, se proponen como contenidos el conocimiento de la historia familiar, los hitos, las tradiciones y la configuración de la sociedad chilena, así como de las costumbres locales y regionales. No se fomentan perspectivas de pensamiento crítico, o los espacios para generar las transformaciones ante las desigualdades por razones de discriminación de raza (Quijano, 2000).

Las bases, en efecto, plantean uno de sus apartados llamados «respeto y valoración de la diversidad humana», la cual pretende generar en los estudiantes la valoración y la conciencia en torno a la diversidad humana y cultural a fin de «lograr una sociedad más inclusiva» (MINEDUC, 2018, p. 18). En efecto, el objetivo primordial «busca que los estudiantes sean capaces de reconocer la riqueza de la diversidad y de comprender que el género, el origen étnico, las creencias o el nivel socioeconómico, entre otras, no deben ser objeto de discriminación o de diferencia de oportunidades» (MINEDUC, 2018, pp. 30-33). Lo anterior, podría definirse por ejemplo enmarcado en la perspectiva crítica de Walsh (2012), no obstante, se generan diversas contradicciones y problemas en los programas de estudio (lo que se verá más adelante).

En el programa de estudio de segundo medio de enseñanza secundaria, el Objetivo de Aprendizaje (OA) 21, propone una serie de metas, entre las que se nombran las «[...] demandas de derechos de grupos históricamente discriminados 
[...] $»^{2}$ (MINEDUC, 2013b, p. 196). Es más, en el OA25 se ahonda en el «reconocer la diversidad inherente a las sociedades como manifestación de la libertad y de la dignidad humana, y evaluar las oportunidades y desafíos que un mundo globalizado entrega para evitar toda forma de discriminación, sea por raza o etnia, nacionalidad, situación socioeconómica, religión o creencia, género, orientación sexual o discapacidad, entre otras» (MINEDUC, 2013b, p. 249).

De ahí que los contenidos señalados tengan relación con la "propuesta de soluciones» para evitar las situaciones de discriminación, la relevancia de las leyes anti-segregación que existen en el ordenamiento jurídico chileno e internacional, así como la importancia de la diversidad humana para la convivencia y estabilidad social. No obstante, tales propuestas son comprendidas desde las estructuras raciales del sistema oficial, manteniendo el statu quo en torno a las desigualdades existentes (Quijano, 2000; Spivak, 2012).

Entre los contenidos que se proponen trabajar, la propuesta del programa de estudio de segundo básico de primaria se enmarca en el análisis de los derechos humanos y las demandas de las «personas pertenecientes a pueblos originarios, diversidades sexuales, con discapacidad, género femenino, entre otros, promoviendo el respeto y defensa de la igualdad de derechos esenciales de todas las personas» (MINEDUC, 2013b, p. 196). Se destaca que, aunque se propone la reflexión sobre las demandas de los pueblos aborígenes, no se sitúa la problematización a la luz de las estructuras sociales actuales, las cuales, como se ha visto, han sido instauradas desde lógicas coloniales. De ahí que, si se reflexiona sobre las demandas de los pueblos originarios, necesariamente se debería reflexionar desde una perspectiva decolonial en base a las jerarquías, las marginaciones y las desigualdades que se han perpetuado, producido y reproducido en la larga duración histórica (Fontana, 2012; Fraser, 2008).

Lo anterior da cuenta de que la propuesta ministerial está enfocada, en efecto, en la promoción de una enseñanza para el reconocimiento de la diversidad cultural, y en este sentido, los procesos de multiculturalidad. Se refiere como multiculturalidad, ya que la propuesta no refleja el desarrollo del pensamiento crítico ni perspectivas críticas (Walsh, 2012; Fraser, 2008; Quijano, 2014). Al contrario, se plantean argumentos, contenidos y objetivos desde lo que serían las perspectivas funcionales al sistema dominante, siguiendo los planteamientos de Walsh (2012).

Aunque se plantea una línea de Formación Ciudadana que propone que la educación se enfoque en dotar a los y las alumnas de habilidades y conocimientos para participar de manera activa y responsable en la sociedad, no obstante, la organiza-

2 El OA21 en rigor está compuesto por: "Analizar la sociedad chilena posterior a la recuperación de la democracia, considerando la estructura social, la disponibilidad y el acceso a bienes, la infraestructura, los medios y las tecnologías de comunicación, el sistema educacional, el mercado del trabajo y la demanda de derechos de grupos históricamente discriminados, entre otros» (MINEDUC, Programa de Estudio 2. Medio, 196). 
ción curricular está enfocada en la educación cívica y la mantención de las estructuras sociales tradicionales. Las líneas tratadas dan cuenta que se propone la valoración de las instituciones públicas y privadas, los poderes del Estado, la Constitución, el sistema de elecciones, entre otros aspectos que dan cuenta de una formación cívica tradicional por sobre una formación para la ciudadanía y la enseñanza de la participación crítica.

\section{a. Los objetivos y los contenidos en el currículo chileno}

En cuanto al planteamiento de los contenidos, la línea de historia está enfocada en las perspectivas educativas tradicionales con altos contenidos políticos, económicos y militares (Marolla, 2014; Marolla, 2019). Los protagonistas son los hombres blancos occidentales y exitosos. En general, las personas en situación de pobreza, marginadas, migrantes y disidentes sexuales y representantes de la diversidad de género están ausentes en los contenidos propuestos para la enseñanza (Mclntosh, 2005; Woyshner, 2002).

Entre los objetivos de aprendizaje del Programa de Estudio de Primero Básico de enseñanza primaria, se da amplio énfasis por ejemplo en el OA5 de «Reconocer los símbolos representativos de Chile (como la bandera, el escudo y el himno nacional), describir costumbres, actividades y la participación de hombres y mujeres respecto de conmemoraciones nacionales (como Fiestas Patrias, Día del Descubrimiento de dos mundos y Combate Naval de lquique) [...]» (MINEDUC, 2013a, p. 122), todos los cuales están acompañados de contenidos que resaltan aspectos como la «unidad nacional», o los "grandes hombres» como «Cristóbal Colón» o «Arturo Prat» (MINEDUC, 2013a, p. 122).

Las expresiones culturales son tratadas a fin de graficar y dar cuenta de la «unidad nacional» y las "expresiones» como país. El programa pretende transmitir una identidad homogénea basada en un concepto determinado sobre el "ser chileno", excluyendo la diversidad, la heterogeneidad y las distintas culturas que conviven en el país. Por ejemplo, en el OA6, se señala que se pretende «conocer expresiones culturales locales y nacionales (como comidas, flores y animales típicos, música y juegos, entre otros), describir fiestas y tradiciones importantes de nivel local (como Fiesta de la Tirana, Fiesta de San Pedro, Fiesta de Cuasimodo, carreras a la chilena, el rodeo, la vendimia [...] y reconocer estas expresiones como elementos de unidad e identidad local y/o nacional» (MINEDUC, 2013a, p. 122), de ahí que tales propuestas de objetivos podrían ser trabajadas y reflexionadas desde las problemáticas de la interculturalidad y sus interacciones con la sociedad chilena dominante, blanca y jerárquica. Sin embargo, se trabajan desde una perspectiva funcional al sistema dominante (Walsh, 2012), es decir, a la «identidad chilena» y las expresiones que la conforman.

El apartado que se incluye en cuanto objetivos a trabajar sobre la interculturalidad se encuentra entre los últimos referidos. El OA12 promueve el «conocer 
cómo viven otros niños en diferentes partes del mundo por medio de imágenes y relatos, ubicando en un globo terráqueo o mapamundi los países donde habitan, y comparando su idioma, vestimenta, comida, fiestas, costumbres y principales tareas con las de niños chilenos" (MINEDUC, 2013a, p. 122). Cabe destacar que tal actividad se realiza desde una perspectiva relacional (Walsh, 2012), donde se entiende la multiculturalidad en función de los parámetros predefinidos por la sociedad y las prácticas de la cultura, así como las prácticas discursivas y de sociabilización chilenas.

En segundo año de primaria, se profundiza en torno a la inclusión de las etnias indígenas. Desde el OA1 se propone «describir los modos de vida de algunos pueblos originarios de Chile en el periodo precolombino, incluyendo ubicación geográfica, medio natural en que habitaban, vida nómada o sedentaria, roles de hombres y mujeres, herramientas y tecnología [...] vivienda, costumbres [...]» (MINEDUC, 2013b, p. 47), y en el OA2 dice "comparar el modo de vida y expresiones culturales de pueblos indígenas presentes en el Chile actual (como mapuche, aimara, rapa nui), con respecto al periodo precolombino, identificando aspectos de su cultura que se han mantenido hasta el presente y aspectos que han cambiado" (MINEDUC, 2013b, pp. 47-48). Lo anterior da cuenta de que se incluye el estudio de las etnias aborígenes, no obstante, su tratamiento no promueve el pensamiento crítico ni la problematización de sus realidades. Al contrario, se insertan dentro de la estructura social dominante y definida por las jerarquías que ya han sido establecidas por la colonialidad. En efecto, se podría decir que se plantea un tratamiento desde una perspectiva funcional (Walsh, 2012), donde se propone su estudio dentro de las estructuras culturales, económicas y las jerarquías políticas.

En el OA3 y el OA4 del Programa de Estudio de Segundo año de Enseñanza secundaria, las ideas referidas anteriormente se reafirman. En el OA3 se plantea «Distinguir los diversos aportes a la sociedad chilena proveniente de los pueblos originarios (palabras, alimentos, tradiciones, cultura, etc.) y de los españoles (idioma, religión, alimentos, cultura, etc.), y reconocer nuestra sociedad como mestiza» (MINEDUC, 2013b, p. 48). En el OA4 se plantea «reconocer y dar ejemplos de la influencia y aportes de inmigrantes de distintas naciones europeas, orientales, árabes y latinoamericanas a la diversidad de la sociedad chilena a lo largo de la historia» (MINEDUC, 2013b, p. 48).

En los objetivos anteriores, a pesar de que se propone el tratamiento de las etnias, los pueblos originarios y sus relaciones, entre otros aspectos, todas ellas son trabajadas desde una visión que reconoce a Chile como una sociedad mestiza, formada a razón de las interacciones entre los distintos pueblos (Quijano, 2000). Aunque lo anterior no deja de ser correcto, no se da énfasis a que, por ejemplo, la construcción del mestizaje o las interacciones en la actualidad no están exentas de conflicto, coyunturas y sometidas a discursos racializados donde la «identidad chilena» se erige como el constructo dominante por sobre las demás manifestaciones, 
las cuales vienen a ser expresiones identitarias subordinadas a la identidad dominante.

En efecto, por ejemplo, en cuarto y séptimo año de primaria se da énfasis a las civilizaciones aborígenes americanas: Mayas, Incas y Aztecas. Se trabajan aspectos ligados a la ubicación geográfica, la organización política, las actividades económicas, las formas de cultivo, costumbres, entre otros aspectos. En efecto, los objetivos se enfocan en el reconocimiento geográfico e histórico de los pueblos aborígenes por sobre su incidencia en las estructuras coloniales y las jerarquías raciales que perduran hasta el día de hoy. Cabe destacar, que en el OA20 en séptimo año de primaria se propone el reconocimiento de «distintas formas de convivencia y conflicto entre culturas en las civilizaciones estudiadas, y debatir sobre la importancia que tienen el respeto, la tolerancia y las estrategias de resolución pacífica de conflictos, entre otros, para la convivencia entre distintos pueblos y culturas» (MINEDUC, 2016, p. 72). Se destaca que en cuanto a la resolución de conflictos que se propone trabajar, los conflictos son trabajados fomentando una perspectiva de homogeneización y transmisión cultural de las jerarquías dominantes y el cómo se insertan en el statu quo.

Cabe resaltar que en quinto año de educación primaria, se encuentra el OA6 que plantea «explicar aspectos centrales de la Colonia, como la dependencia de las colonias americanas de la metrópoli, el rol de la Iglesia Católica y el surgimiento de la una sociedad mestiza» (MINEDUC, 2013c, p. 48), el cual se complementa al OA7: «explicar y dar ejemplos de las distintas formas en las que españoles y mapuches se relacionaron en el periodo colonial, considerando resistencia mapuche y guerra de Arauco, mestizaje, formas de trabajo (como encomienda y esclavitud), evangelización, vida fronteriza y sistema de parlamentos» (MINEDUC, 2013c, p. 48). En efecto, en el $\mathrm{OA} 12^{3}$ se plantea el conflicto mapuche-español dentro de la visión occidental de la historia. Se propone la problemática desde la construcción historiográfica y problematizadora oficial, sin proponer las visiones, la historicidad y las perspectivas de los pueblos aborígenes.

Al respecto, a pesar de las propuestas de los objetivos, el énfasis entregado al OA6 promueve contenidos enfocados en las divisiones políticas administrativas, el sincretismo, las festividades y la conformación de la sociedad mestiza. De igual manera, el OA7 indaga la guerra entre mapuches y españoles, los procesos ocurridos durante la colonia, las formas de trabajo colonial, entre otros aspectos sin entrar en los conflictos actuales que viven los mapuches, ni las jerarquías establecidas desde la colonialidad. Como afirma Walsh (2012), la colonialidad es una estructura

${ }^{3}$ El OA12 del curso de Octavo básico de educación primaria dice: «analizar y evaluar las formas de convivencia y los tipos de conflicto que surgen entre españoles, mestizos y mapuches como resultado del fracaso de la conquista de Arauco, y relacionar con el consiguiente desarrollo de una sociedad de frontera durante la colonia en Chile». (MINEDUC, Programa de Estudio 8.은 Básico, 72). 
de larga duración histórica, desde donde se han impuesto estructuras raciales de comportamiento, cultura y discurso basadas en los prejuicios de la piel y el origen étnico, las cuales han colaborado en la configuración de la sociedad actual (Tubino, 2005).

El resto de la organización de los cursos se rige bajo parámetros clásicos de la enseñanza de la historia: historia antigua, medieval, moderna, guerras mundiales, dando énfasis a temas clásicos, como la democracia, los juegos olímpicos, el comercio medieval, los héroes, entre otros aspectos (Marolla, 2019). Existe un alto contenido político de los temas que se trabajan, con algunas breves incursiones sobre el sistema democrático y la participación de las mujeres en el sufragio, el quiebre de la democracia y el "régimen militar» ${ }^{4}$. Para los últimos cursos, tanto tercero y cuarto año de enseñanza secundaria no dan cuenta de la inclusión de aspectos relacionados a la interculturalidad. Los objetivos y los contenidos se enfocan en procesos políticos, la constitución, el sistema democrático, las elecciones, los poderes del Estado, el Gobierno, el rol de las Fuerzas Armadas, el sistema económico, el mercado del trabajo y breves tratamientos a los Derechos Humanos desde una perspectiva política y como compromiso estatal a nivel nacional e internacional (Marolla y Pagès, 2015).

\section{El CURRÍCULO DE ARGENTINA. PROGRAMAS DE CIENCIAS SOCIALES $Y$ EL DE FORMACIÓN ÉTICA Y CIUDADANA}

En el nivel inicial de los Núcleos de Aprendizaje Prioritarios (NAP), se proponen entre los aprendizajes iniciales el «propiciar la conformación de identidad personal y colectiva, promoviendo el reconocimiento de culturas, lenguajes e historias personal, familiar, local, provincial, regional y nacional» (NAP, 2018a, p. 13). Los NAP del ciclo de Educación Primaria de Ciencias Sociales de los tres primeros años, en este sentido, ofrecen situaciones de enseñanza que se podrían enfocar en los planteamientos de la interculturalidad: «el proceso de construcción de la identidad nacional y el respeto por la diversidad cultural». El resto de los aprendizajes se enfocan en el aprendizaje del territorio, el trabajo, el medioambiente y el sistema económico, entre otros aspectos.

En específico, en los contenidos que se plantean para segundo año de secundaria, hay pocas referencias a la diversidad o la multiculturalidad. Solo se plantea en el apartado "en relación con las actividades humanas y la organización social», se sugiere trabajar desde el planteamiento del «conocimiento de que, en el mundo actual, conviven grupos de personas con diferentes costumbres, intereses, orígenes, que acceden de modo desigual a los bienes materiales y simbólicos (tomando

\footnotetext{
${ }^{4}$ Cabe destacar que en el libro se menciona como «Régimen Militar» y no como «Dictadura».
} 
ejemplos de nuestro país y de otros países del mundo)» (NAP, 2018b, p. 32). En efecto, la visión que se entrega es propuesta para analizar desde las lógicas construidas por la historia argentina, las estructuras coloniales y las jerarquías culturales definidas por los hombres blancos. Es posible afirmar que el tratamiento que se da es desde una perspectiva relacional (Walsh, 2012).

En el resto de la programación no se presentan atisbos o propuestas al tratamiento de los procesos interculturales. El programa está compuesto de contenidos ligados a los aspectos políticos, las formas de trabajo, el mercado, las actividades comerciales, el espacio geográfico, entre otros aspectos que formarían parte de la organización tradicional de la enseñanza de la historia y las ciencias sociales (Marolla, 2014).

Por otra parte, en los programas NAP de «Formación Ética y Ciudadana» del Primer Ciclo de Educación Primaria, se ofrecen espacios, objetivos y aprendizajes enfocados en el tratamiento y reflexión de los procesos interculturales: «el reconocimiento de los aspectos comunes y diversos en las identidades personales, grupales y comunitarias, en el marco de una concepción que enfatice la construcción sociohistórica de las mismas, para promover la aceptación de la convivencia en la diversidad» (NAP, 2018c, p. 58). El programa propone, además, la: «reflexión en torno a la dimensión ética, política e intercultural de saberes de las diferentes áreas y de temas transversales [...]» (NAP, 2018c, p. 58).

En efecto, los objetivos propuestos desde el área de Formación Ética y Ciudadana fomentan la reflexión crítica, la participación democrática, la formación ciudadana, la construcción de los procesos de libertad, paz, solidaridad, igualdad, justicia, bien común, respeto a la diversidad, la importancia del dialogo para la solución de problemas, entre otros. Los contenidos que se incluyen dan cuenta de las iniciativas para trabajar desde la interculturalidad: «el reconocimiento de las diferencias personales y el respeto de las mismas en la interacción con los otros»; "el reconocimiento de diversas formas de prejuicios, de maltrato y/o discriminación, en situaciones cotidianas de desconocimiento, negación y/o abuso sobre personas o grupos» (NAP, 2018c, p. 59), entre otros que ahondan en las propuestas sobre la reflexión en las aulas en torno a los procesos de la interculturalidad, las identidades, la discriminación y la justicia.

De manera similar, los NAP del segundo ciclo de Formación Ética y Ciudadana incluyen objetivos y aprendizajes enfocados en el análisis de la interculturalidad «el reconocimiento de los aspectos comunes y diversos en las identidades personales, grupales y comunitarias, en el marco de una concepción que enfatice su construcción sociohistórica, para valorar la convivencia en la diversidad» y "la reflexión en torno a la dimensión ética, jurídica, política y cultural de saberes de las diferentes áreas y de temas relevantes tales como: Educación Ambiental, Educación Vial, Educación para la Salud, Educación Sexual, Educación para la Paz, Educación Intercultural [...]» (NAP, 2018c, pp. 80-81), así como el resto de objetivos que tienen relación 
con la participación, la autonomía, las situaciones de desigualdad y el respeto por la diversidad, entre otros aspectos que podrían enfocarse y plantearse desde las problemáticas de la interculturalidad (Tubino, 2005; Quijano, 2000).

Además de los contenidos antes mencionados, destacan los del tercer año de Formación que proponen espacios de análisis y de reflexión en torno a la interculturalidad y las identidades, tales como «el respeto y la valoración de las diferencias interpersonales, iniciándose en el reconocimiento de la diversidad de identidad y proyectos de vida -personales y/o colectivos-, que coexisten en diferentes contextos»; "el reconocimiento de diferentes formas de prejuicio, maltrato y/o discriminación, en situaciones cotidianas y/o ficcionales, distinguiendo, mediante la discusión grupal, la multiplicidad de causas, elementos, relaciones y modalidades que operan en estos procesos»; "la comprensión de los símbolos que expresan las identidades grupales, locales, regionales y/o nacionales y como construcciones históricas colectivas» (NAP, 2018c, pp. 63-64) y así como del segundo ciclo se destaca el contenido «el reconocimiento de la preexistencia de los pueblos originarios, de sus expresiones culturales, de sus cosmovisiones y sistemas valorativos [...]» (NAP, 2018c, p. 83).

Lo anterior, aunque no se podría enmarcar en una perspectiva crítica de la interculturalidad, según las categorías propuestas por Walsh (2012), representa un gran esfuerzo por problematizar las estructuras bajo las cuales se han trabajado e incluido tales temas y problemas. Los aprendizajes y los objetivos propuestos son amplios, lo que podría facilitar el planteamiento de actividades, estrategias y perspectivas por parte del docente, incluso, la promoción y reflexión de tales problemáticas desde una perspectiva crítica y transformadora ${ }^{5}$. Cabe destacar, por ejemplo, que los NAP del segundo ciclo de Formación Ética y Ciudadana consideran trabajar con los «Símbolos y conmemoraciones que expresan identidades y valores grupales, locales, regionales y/o nacionales como construcciones históricas colectivas (los escudos, las banderas, los pañuelos blancos, la cinta roja en la lucha contra el SIDA, la bandera multicolor del mutualismo, las banderas de los pueblos originarios, entre otros) [...]» (NAP, 2018c, p. 89).

Los otros objetivos y aprendizajes están relacionados con la democracia argentina, la importancia del dialogo, la división territorial-geográfica, la administración y organización del país, las instituciones, los derechos y deberes del ciudadano, los modelos económicos, entre otros temas que se pueden insertar en los modelos tradicionales de la enseñanza tradicional de la historia. Entre los contenidos propuestos relacionados al tratamiento de la interculturalidad, es posible señalar que se presentan para trabajar: «el conocimiento de los derechos de las minorías y de responsabilidad del Estado frente a situaciones de discriminación y violación de

${ }^{5}$ Cabe destacar, de todas maneras, que tales contenidos no son trabajados en el área de Historia y Ciencias Sociales, sino que en el área de Formación Ética y Ciudadanía. 
derechos» y "la reflexión y la comparación entre diversas manifestaciones culturales en las sociedades latinoamericanas, promoviendo el respeto y la valoración de la diversidad» (NAP, 2918e, p. 51).

Como se ha podido vislumbrar, los objetivos y los contenidos propuestos se enmarcan dentro de las estructuras dominantes de la historia argentina, donde no existen mayores espacios para la reflexión sobre lo establecido ni la formación del pensamiento crítico. En efecto, el análisis sobre la diversidad cultural es realizado desde lo que define Walsh (2012) como perspectiva relacional y perspectiva funcional, ambas en interacción. Lo fundamental del programa es entregar una formación en torno a contenidos clásicos como la política, la administración, la economía, las exportaciones, el trabajo, entre otros que figuran y dan relevancia a los hombres blancos, dominantes y exitosos, por sobre la historicidad de las etnias, los aborígenes, los problemas (Marolla, 2019), conflictos y otros que existen desde la colonialidad hasta el día de hoy en la sociedad argentina (Quijano, 2000; Walsh, 2012).

En los programas NAP del segundo ciclo de Educación Primaria de Ciencias Sociales, en relación a la formación en interculturalidad se propone el objetivo de: «la construcción de una identidad nacional respetuosa de la diversidad cultural» (NAP, 2018d, p. 44). De manera similar, los NAP del ciclo básico de Educación Secundaria de Ciencias Sociales incluyen algunas temáticas que se podrían llegar a relacionar con la interculturalidad: "La construcción de una identidad nacional plural respetuosa de la diversidad cultural, de los valores democráticos y de los derechos humanos» (NAP, 2018f, p. 12). No obstante, tales temáticas son breves planteamientos sobre lo que sería la interculturalidad. Al contrario, la interculturalidad es trabajada desde las perspectivas oficiales de la historia y del Estado, sin problematizar ni cuestionar las bases del proceso histórico (Quijano, 2000).

Se destaca que el ciclo secundario ahonda en objetivos y aprendizajes que tienen relación con la democracia, la organización política de la sociedad argentina, la participación ciudadana y crítica, la resolución de problemas, el patrimonio, el territorio y los problemas medioambientales, entre otros. Todo lo que marca una diferencia con los objetivos y los aprendizajes tratados y trabajados en el ciclo primario. En efecto, las conexiones entre los temas es posible que promuevan, desde distintos enfoques, un análisis en mayor profundidad sobre la interculturalidad. No obstante, tales procesos son comprendidos desde las lógicas de la sociedad y la historicidad argentinas. Esto quiere decir que son trabajadas desde la perspectiva funcional (Walsh, 2012).

Entre los contenidos propuestos para trabajar, es posible mencionar «el análisis de las formas de organización de las sociedades indígenas en relación con la organización de los trabajos, la distribución del excedente, la jerarquización social, la legitimación a través del culto y de los sistemas de creencias, a partir del tratamiento de uno o dos casos» (NAP, 2018f, p. 16). No obstante, a pesar de que tales objetivos son factibles de ser trabajados desde perspectivas críticas, el enfoque 
ofrecido ahonda en temas tradicionales como los viajes europeos, el proceso de conquista española, la monarquía, la economía colonial, la Revolución Francesa, la Revolución Industrial y los procesos de Independencia en América. Todos los cuales están enfocados en aspectos políticos, económicos y militares de la historia tradicional argentina. Para el segundo y tercer año los contenidos incluyen «el conocimiento de la diversidad cultural en la Argentina y la comprensión de los principales procesos de diferenciación y homogeneización en los sistemas de conocimientos y creencias, valores, prácticas y tradiciones, atendiendo a sus manifestaciones en distintas regiones y lugares del país» (NAP, 2018f, p. 18).

Los contenidos anteriores se insertan dentro de distintas materias que quedan a disposición del docente en cuanto al tratamiento a efectuar, por lo que no se da profundidad ni prioridad dentro del programa. Además, la propuesta de la interculturalidad es promovida desde las definiciones de la cultura argentina. Es decir, las estructuras jerárquicas son definidas desde la colonialidad, donde las etnias, los aborígenes, así como las migraciones, son tratadas desde las lógicas funcionales (Walsh, 2012) al sistema construido por la sociedad argentina, lo cual se pretende transmitir, producir y reproducir en la educación ${ }^{6}$.

En el ciclo básico de educación secundaria, los NAP de Formación Ética y Ciudadana ofrecen distintos objetivos y contenidos relacionados al trabajo con la interculturalidad. En efecto, se pueden mencionar «la valoración reflexiva de los aspectos comunes y diversos de las identidades comunitarias como aporte a una identidad nacional y regional (latinoamericana) abierta, plural y dinámica, como construcción sociohistórica resultante de procesos de luchas fácticas y simbólicas»; "la identificación y análisis ético de las desigualdades sociales, económicas y de género, en situaciones de diversidad social y cultural» (NAP, 2018g, pp. 15-16).

En el tratamiento dado durante el ciclo de educación primaria, se fomenta el estudio de las problemáticas, la educación para la salud, educación ambiental, educación intercultural, entre otros. En tal contexto se fomenta la participación de los estudiantes en la construcción de la memoria, los Derechos Humanos y su defensa, la resolución de los problemas, la participación ciudadana, entre otras temáticas que posibilitarían el desarrollo del pensamiento crítico (Apple, 1991; Fraser, 2008).

Se puede destacar el contenido del «reconocimiento de los derechos políticos, sociales, económicos y culturales de los pueblos originarios, los afrodescendientes y otras minorías a partir de las formas de resistencias de estos grupos en la actualidad» (NAP, 2018g, p. 17). Se hace énfasis a tal contenido, ya que se plantea desde el trabajo intercultural fomentando perspectivas críticas según las definiciones de

${ }^{6}$ El resto de los contenidos se refieren al tratamiento de las problemáticas territoriales y medio ambientales, el conocimiento de los procesos de urbanización, la economía en Argentina y un alto énfasis en los distintos tipos de organización política nacional, desde las provincias, regiones y municipios, así como la inserción político-económica en el MERCOSUR. 
Walsh (2012). En efecto, desde tal contenido se puede vislumbrar la apertura hacia el cuestionamiento y la reflexión en torno a los pueblos étnicos, así como los afrodescendientes desde las problemáticas que enfrentan en la actualidad, dando los espacios y las posibilidades educativas de analizar las estructuras de desigualdad establecidas desde la colonialidad y que han performado e invisibilizado a la otredad marginada por una construcción conformada por un grupo definido por los blancos, europeos, occidentales y colonizadores.

Tal contenido se complementa al resto de materias, las cuales promueven aprendizajes en defensa de los Derechos Humanos, la reflexión en torno al género, los medios masivos de comunicación, los derechos laborales, la violencia en la sociedad, la importancia de la diversidad, «la comprensión de las interrelaciones entre diversidad sociocultural y desigualdad social y económica, identificando representaciones hegemónicas de género, de orientación sexual, de nacionalidad, étnicas, religiosas [...]» (NAP, 2018g, p. 18), las que en su conjunto dan los espacios y las posibilidades de cuestionar y reflexionar sobre las estructuras de desigualdad establecidas en la sociedad en torno a las identidades, los grupos étnicos, los afrodescendientes y en general quienes han estado marginados de las estructuras de poder. No obstante, aunque los NAP generan aperturas de perspectivas hacia temas socialmente relevantes, siempre dependerá del tratamiento, las prácticas y las perspectivas que ofrezca el profesorado (Barton, 2010; Castillo, 2011).

\section{EL CURRÍCULO DE COLOMBIA: UNA PROPUESTA DESDE LA INTERCULTURALIDAD}

A continuación, se analizarán los lineamientos curriculares Colombianos de Ciencias Sociales y la Cátedra de estudios Afrocolombianos. Esto resulta interesante, ya que ofrece una propuesta reflexiva enfocada en la multiculturalidad, las etnias y los grupos afrocolombianos.

\section{a. Lineamientos curriculares de Ciencias Sociales}

Los ejes del programa de enseñanza primaria y secundaria consideran esencial «lograr que la educación sirva para el establecimiento, el fomento de la participación ciudadana y la construcción de la convivencia pacífica» (MEN, s. f. a, p. 11). Para el programa resulta interesante destacar que se reconoce la labor de la escuela desde la formación de la ciudadanía y la participación por sobre la enseñanza de las disciplinas: «el objetivo del área de Ciencias Sociales en la Educación Básica y Media no es formar o ayudar a estructurar científicos sociales: historiadores, geógrafos, sociólogos, economistas, entre otros, porque esa es una labor o función específica de la Educación Superior» (MEN, s. f. a, p. 13). 
En efecto, uno de los objetivos y ejes centrales de los programas de primaria y secundaria es: "que las y los estudiantes afronten de manera crítica y creativa el conocimiento científico, tecnológico, artístico y humano que se produce [...] que comprendan la realidad nacional y desarrollen actitudes democráticas, responsables, tolerantes, solidarias, justas y éticas» (MEN, s. f. a, p. 13), lo que da cuenta de los esfuerzos de los programas enfocados en la formación para la ciudadanía participativa y crítica, y en especial, ser agentes capaces de «transformar la sociedad en la que las y los estudiantes se desarrollan-donde sea necesario" (MEN, s. f. a, p. 13). De esa manera, en el contexto de la inclusión de los temas sobre interculturalidad se plantea el reconocimiento desde perspectivas críticas sobre la diversidad: "formar hombres y mujeres que participen activamente en su sociedad con una consciencia crítica, solidaria y respetuosa de la diferencia y la diversidad existentes en el país y en el mundo" (MEN, s. f. a, p. 13). Lo anterior hace notar que se podría plantear el trabajo que pretende realizar el currículo colombiano desde las perspectivas críticas de la interculturalidad (Castillo, 2011; Walsh, 2012).

El programa propuesto está formado desde distintas perspectivas teóricas y epistemológicas que pretenden construir un currículo que, como dice el material, introduzca miradas holísticas y generen rupturas con el énfasis tradicional de la enseñanza de la historia. En este contexto, el programa propone como eje fundamental «reconocer los saberes de las culturas no occidentales, y aceptar el aporte de las minorías dentro de los distintos países para promover una ciencia que reconozca lo "multicultural" y lo intercultural; un reto que tendrán que asumir las Ciencias Sociales, es incorporar otras visiones de mundo en otras sociedades, por ejemplo, el manejo del agua y la tierra que tienen las comunidades indígenas» (MEN, s. f. a, p. 9).

En este contexto, además, se propone, como eje la enseñanza del futuro, la convivencia, los saberes universales frente a los saberes populares y locales y las tensiones en las disciplinas. Tales propuestas resultan interesantes de analizar ya que presentan la conflictividad, así como el reconocimiento de los procesos interculturales colombianos e internacionales. En efecto, los objetivos del programa pretenden enfocarse en la «comprensión y tratamiento de los problemas sociales» (MEN, s. f. a, p. 10).

Dentro de los planteamientos oficiales, el programa y en conjunto el Ministerio de Educación Nacional (MEN) reconocen distintos ejes fundamentales de enseñanza. En torno a la interculturalidad, es posible mencionar el relativo a la "necesidad de priorizar los principios de calidad, equidad y reconocimiento de la diversidad en la educación y en los procesos educativos del país, como prácticas que pueden generar transformaciones de carácter social y cultural» (MEN, s. f. a, p. 43). Se entiende la diversidad como aquel contenido y objetivo que permite a los estudiantes reflexionar y criticar ante las desigualdades (Castillo y Rojas, 2007). Esto se condice con la prioridad en la fundamentación de las orientaciones curriculares para las ciencias sociales de Educación primaria y secundaria, las que 
se definen como: «una estructura abierta, flexible, integrada y en espiral» (MEN, s. f. a, p. 46).

En efecto, uno de los ejes relevantes dentro del programa es: «La Defensa de la condición humana y el respeto por su diversidad: multicultural, étnica, de género y opción personal de vida como recreación de la identidad colombiana» (MEN, s. f. a, p. 54). Según el programa, al respecto la educación colombiana se compromete de manera obligatoria a: «dar cabida en la escolarización a minorías sociales, étnicas y culturales, plantea por una parte el problema de la educación multicultural y por otra, el más amplio y significativo, de la capacidad de la educación para acoger la diversidad» (MEN, s. f. a, p. 55). Ante el objetivo propuesto, el programa reconoce que tienen que enfrentar problemas como la homogeneización y la normalización educativa y social que ha sido transversal históricamente (Castillo y Rojas, 2007; Castillo, 2011; Tubino, 2005).

\section{b. El Currículo Colombiano: Cátedra estudios afrocolombianos}

El programa se inicia desde el reconocimiento de que la multiculturalidad y la plurietnicidad de los pueblos de América son procesos que siempre han estado presentes, no obstante, han adquirido visibilidad desde la educación y la política en los últimos años. Se reconoce que con la promulgación de la Constitución de 1991 y el reconocimiento de que el Estado tiene un carácter pluriétnico y multicultural, se generó un cambio en cuanto el respeto a la diversidad. En efecto, el programa se basa en que se debe: "construir así la democracia desde la perspectiva del conocimiento y reconocimiento de las demás culturas, sin perder la conciencia de la singularidad de la cultura propia, compromete fundamentalmente la educación. Es a ella a la que le corresponde formar ciudadanos y ciudadanas capaces de responder al tiempo, a la imperiosa necesidad de una conciencia nacional y mundial, y al afianzamiento de su propia identidad» (MEN, s. f. b, p. 2).

El programa considera dos líneas generales, la etnoeducación desde la realidad y esperanza de los pueblos indígenas y afrocolombianos, y el rescate de la educación de las Comunidades Afrocolombianas. Resulta interesante que el currículo reconoce la gran diversidad que existe en el país, la cual se materializa en sus creencias, costumbres, tradiciones, fiestas, música, danzas, entre otras expresiones.

La etnoeducación se reconoce como una política estatal y educativa fijada en la Constitución Política de $1991^{7}$. Se basa en el reconocimiento y la proyección de la diversidad étnica y cultural, la importancia de las lenguas y dialectos, así como la inclusión del bilingüismo, la protección de la identidad cultural y derechos de las

${ }^{7}$ La Constitución Política de 1991 fija en la Ley 70 de 1993, Ley 115 de 1994 y en los Decretos Reglamentarios de 804 de 1995 y 1122 de 1998. El Estado reconoce el carácter multiétnico y pluricultural del país. 
comunidades negras, entre otros aspectos. Se destaca que en los lineamientos curriculares se reconoce que en Colombia existen múltiples regiones con distintas expresiones culturales, como los Rom o Gitanos. Por ende, el programa reconoce que la interculturalidad es esencial para llevar a cabo procesos sociopolíticos de paz.

En los objetivos que guarda el programa ${ }^{8}$ destacan aspectos como el rescate de los saberes tradicionales de cada pueblo, el cambio metodológico desde perspectivas interculturales, el reconocimiento de las identidades ausentes, la reflexión en torno a los prejuicios y los estereotipos en torno a las diversidades étnicas y culturales, fomentar la etnoeducación en el país, así como fomentar las perspectivas afrocolombianas y étnicas con foco educativo (Castillo, 2011; Hall, 1997). De hecho, el programa afirma que gran parte de la «literatura afrocolombiana es oral; es por esto que la tradición y la literatura oral se debe rescatar, mantener y explorar como depositaria de la vida espiritual acumuladora de experiencias y conocimientos propios y constructora de memoria colectiva que no envejece» (MEN, s. f. b, p. 17).

Resulta interesante notar el tratamiento social que se da al término afro, así como a las comunidades étnicas en Colombia. En efecto, se dice que el «prefijo afro hace referencia a la herencia cultural africana que pervive en la memoria colectiva a través de distintos saberes y prácticas, sobre todo en la tradición oral, la memoria corporal, que incluye los gestos, la danza, las palabras, el arte, la música, los cantos, y su relación con la naturaleza. Es el pasado ancestral, elemento clave de su identidad étnica hoy» (MEN, s. f. b, p. 12).

Se afirma que los términos, en general, se han impuesto desde la otredad (Castillo, 2011). En estos marcos, el programa reconoce que los afrocolombianos son parte de la construcción del país y las luchas contra «la discriminación racial pero igualmente contra la injusticia social» (MEN, s. f. b, p. 12). Para el currículo, la inclusión de sus problemas destaca debido a que es un trabajo de «resignificación y redignificación de los ancestros y de sus descendientes en el presente, no es sim-

8 a) conocer y exaltar los aportes histórico-culturales, ancestrales y actuales de las comunidades afrocolombianas a la construcción de la nación colombiana; b) reconocer y difundir los procesos de reintegración, reconstrucción, resignificación y redignificación étnica y cultural de los descendientes de los africanos esclavizados en Colombia, en la perspectiva de nuevas lecturas sobre la configuración de la identidad nacional; c) aportar al fortalecimiento de la identidad, autorreconocimiento y autoestima de los colombianos en el contexto del sentido de pertenencia a la nación colombiana; d) propiciar el desarrollo de actitudes de comprensión y respeto de la diversidad étnica y cultural existente en el país, proscribiendo los prejuicios y estereotipos discriminatorios; e) replantear los enfoques pedagógicos y didácticos que orienten la elaboración de textos y materiales de estudio en relación con la realidad del africano, afroamericano y particularmente de lo afrocolombiano; f) ayudar al proceso de desarrollo y consolidación de la etnoeducación en el país; g) plantear criterios para la formación y evaluación de docentes con el referente de la diversidad étnica y cultural de la Nación y; h) crear las condiciones para el desarrollo de la cátedra internacional afroamericana. 
plemente un reencuentro con el pasado sino un reto ante el futuro de la Nación» (MEN, s. f. b, p. 12).

El programa entiende la etnoeducación no como una enseñanza que venga a sustituir los saberes ancestrales, al contrario, la propuesta nace desde la interculturalidad a fin de interrelacionar tales conocimientos con las distintas culturas y etnias presentes en el país. Al respecto, se reconoce la complejidad del trabajo desde la interculturalidad y la importancia del contexto educativo. Se afirma la complejidad de la enseñanza intercultural, no obstante, se plantea que: «la transversalidad es compleja y, por ende, no se puede reducir a selección de algunos contenidos temáticos afrocolombianos con la lógica de su organización en torno a asignaturas. El ejercicio de inserción de contenidos temáticos por áreas y niveles educativos lo deben hacer los propios maestros, considerando las realidades particulares regionales y de las instituciones escolares» (MEN, s. f. b, p. 24).

El currículo de la Cátedra de Estudios Afrocolombianos afirma que la etnoeducación es una rama que debe ser ofrecida en todos los programas de formación de docentes: «los temas y problemas étnicos y culturales no son solo de interés de las Ciencias Sociales y Humanas, también son de la competencia de las Ciencias Naturales y las Matemáticas» (MEN, s. f. b, p. 27) ${ }^{9}$.

\section{CONCLUSIONES}

A modo de conclusión es posible plantear algunas ideas relacionadas a los objetivos y las preguntas esgrimidas en un inicio a la luz del análisis y la reflexión realizada sobre los materiales educativos. Como dice Rüsen (2005), la historia debe ser un conocimiento útil para las personas. Es decir, la enseñanza de la historia debe plantearse desde el potencial educativo para la formación de la ciudadanía. Como afirma García y De Alba (2009) la educación para la ciudadanía es un eje y un proceso fundamental con el fin de promover cambios en la sociedad. Miralles y Gómez (2017) coinciden al respecto y agregan que la enseñanza de la historia y las ciencias sociales debe colaborar en problematizar los prejuicios y los estereotipos que se han construido en torno a las etnias, los migrantes y los afrodescendientes.

En cuanto al currículo de Chile, se propone en general, desde las bases el reconocimiento de la diversidad entre sus ejes para la educación primaria. Se prioriza la empatía, la identidad, la pertenencia a una comunidad y la valoración de la otredad. El fin del currículo se plantea desde la lucha contra la discriminación y la inclusión social. Todo ello en contraste a contenidos que proponen una

${ }^{9}$ Lo anterior se complementa con lo dispuesto en el Artículo 58 del Decreto 804/95: «El Estado promoverá y fomentará la formación de educadores en el dominio de las culturas y lenguas de los grupos étnicos, así como programas sociales de difusión de las mismas» (27). 
historia tradicional enfocada en la historia familiar, los hitos, las tradiciones y las costumbres locales y regionales. Se propone la valoración de las instituciones y los poderes del Estado, la Constitución, entre otros aspectos que dan cuenta del fomento de educación cívica por sobre la formación para la ciudadanía (Marolla, 2014; Marolla, 2019).

Los contenidos, en este sentido, se enfocan en perspectivas tradicionales desde temas políticos, económicos y militares (Marolla y Pagès, 2015). Los protagonistas son los hombres blancos, occidentales y que tienen poder. En este contexto, son marginadas las etnias, los migrantes, los afrodescendientes, la diversidad de género, entre otros que no encajan en las estructuras de poder legadas desde la colonialidad. En efecto, la inclusión que se realiza sobre las culturas y la otredad es concebida desde la perspectiva funcional (Walsh, 2012), donde se pretenden trabajar las ubicaciones geográficas, los tipos de cultivo, los roles, las viviendas, entre otros aspectos que no fomentan el pensamiento crítico ni reflexivo. No se incluyen sus problemáticas, las luchas sociales que han ocurrido, los problemas en torno a la discriminación, la transmisión de prejuicios y estereotipos en torno a los migrantes, las etnias y los afrodescendientes, provocando un currículo tradicional y excluyente de la diferencia (Castillo, 2011; Quijano; 2000).

La perspectiva desde la que se trabaja el currículo chileno, así como los contenidos planteados, aunque se incluyen distintas visiones sobre los migrantes y las etnias, se hacen presente manteniendo el statu quo social, perpetuando las estructuras que posicionan a los hombres blancos con poder por sobre las etnias y los migrantes, quienes son visualizados de manera subordinada a la historia oficial y las perspectivas de quienes han performado el poder. Como dice Walsh (2012), las estructuras impuestas desde la colonialidad han perdurado durante la historia, basando los prejuicios y los estereotipos en condiciones raciales.

Lo anterior, se condice con lo que se plantea en el currículo de Argentina. No obstante, los NAP curriculares de tal país presentan dos perspectivas. Por un lado, desde la enseñanza de la historia y las ciencias sociales, aunque se propicia la formación de la identidad personal, colectiva y se promueve el reconocimiento de las culturales, los lenguajes y la diversidad étnica, migrante y de los afrodescendientes, en los contenidos se encuentran pocas referencias al tratamiento de la interculturalidad. En general, el programa, los objetivos y sus contenidos, se componen de aspectos políticos, económicos y militares con protagonistas hombres, blancos y poderosos (Barton, 2010). Por lo anterior, es posible plantear que el currículum NAP está construido desde lógicas funcionales y relacionales según los modelos de Walsh (2012). La interculturalidad es tratada sin alterar las estructuras legadas desde la colonialidad, donde las etnias, los migrantes y los afrodescendientes son presentados de manera subordinada a una historia que se presenta de manera oficial y que invisibiliza las perspectivas y la historicidad desde la otredad (Castillo, 2011; Quijano, 2000; Fontana, 2002). 
Por otra parte, en los NAP de "Formación Ética y Ciudadana» se ofrecen distintos espacios materializados en objetivos, contenidos y actividades que proponen la construcción histórica desde las perspectivas de las etnias, los migrantes y los afrodescendientes. Así, se incluyen materias sobre los Derechos Humanos, el género, la violencia y la importancia de la diversidad social. Por ejemplo, se sugiere el análisis de las identidades, los pueblos originarios, las cosmovisiones, las expresiones culturales, destacando las estructuras de discriminación, los prejuicios y los estereotipos que se han generado en la sociedad. Lo anterior es tratado con fines de reflexión y análisis a fin de que se propongan perspectivas de transformación ante las desigualdades sociales que existen. Desde ahí que sea posible plantear que tales programas varían entre las perspectivas funcionales y críticas de Walsh (2012) ya que se incluye la participación, así como el análisis en torno a las situaciones que han generado problemáticas sociales que, en especial, han marginado a la diversidad étnica, migrante y afrodescendiente (Castillo, 2011; Castillo y Rojas, 2007). No obstante, en algunos espacios se plantea una enseñanza que no cuestiona las estructuras sociales dominantes legadas desde la colonialidad (Quijano, 2000).

En cuanto al análisis del currículo colombiano, es posible afirmar que genera un planteamiento innovador respecto a los programas de los países anteriores. En efecto, se propone en sus bases que la educación debe colaborar para la formación ciudadana, la convivencia pacífica y el reconocimiento de las etnias, los migrantes y los afrocolombianos. El currículo promueve, así, que los estudiantes puedan empoderarse de manera crítica ante las desigualdades sociales, las discriminaciones y las exclusiones. Cabe destacar que el programa se plantea desde perspectivas que reconocen que el conocimiento ha sido construido desde lógicas occidentales, por lo que sus planteamientos se enfocan en posicionar lo multicultural como un conocimiento que ha sido invisibilizado por las estructuras coloniales occidentales. Es interesante, de ese modo, que el programa se plantea desde el rescate de la historicidad de las minorías que han sido ausentadas y subordinadas tradicionalmente por los grupos dominantes (Fraser, 2008; Quijano, 2014; Romero, 2010).

En una perspectiva similar, se debe mencionar que el currículo colombiano incluye un amplio programa, como se ha visto, sobre el rescate de la historicidad, sus perspectivas locales, así como su cultura y cosmovisión. Por ello, la misma constitución de Colombia se reconoce como pluriétnica y multicultural, a fin de dar las posibilidades educativas para el tratamiento y la inclusión desde los marcos de la democracia y la lucha contra la discriminación, los prejuicios y los estereotipos en torno a los afrodescendientes, los pueblos indígenas y la diversidad cultural (Barton, 2010; Castillo y Rojas, 2007; Spivak, 2012). Aunque el currículo reconoce la compleja tarea de incluir la interculturalidad desde perspectivas que propongan la transformación del statu quo, a la vez plantean que es una tarea fundamental para lograr la justicia social (Fraser, 2008; Spivak, 2012). 
Es posible decir que ambos programas colombianos son planteados desde las perspectivas críticas de Walsh (2012), donde se propone la transformación de las desigualdades, la etnoeducación y el posicionamiento del protagonismo de las etnias, los migrantes y los afrodescendientes desde su historicidad. Tal práctica sería un ejercicio de cuestionamiento en torno a las lógicas socioculturales legadas desde la colonia y que perduran hasta el día de hoy en cuanto subordinación, invisibilización y discriminación de la otredad, por lo que resulta interesante la propuesta desde los programas colombianos y los marcos jurídico-constitucionales que se ofrecen desde el reconocimiento de la diversidad (Spivak, 2012; Fraser, 2008; Woyshner, 2002).

A pesar de que se planteen currículos desde perspectivas críticas, relacionales o funcionales según las categorías de Walsh (2012), es sabido que el currículo funciona de modo prescriptivo y condicionante ante las prácticas que se realizan. Ante tal escenario, es fundamental que la formación del profesorado sea desde lógicas que reconozcan la importancia de la inclusión de la interculturalidad y sus problemas. El currículo debería estar alineado a prácticas docentes desde perspectivas críticas que persigan la transformación de las desigualdades, la lucha contra los prejuicios, los estereotipos y, sobre todo, el empoderamiento y la participación de la ciudadanía en la lucha por la justicia social y el reconocimiento de las identidades, las etnias, los migrantes y los afrodescendientes dentro de las estructuras tradicionales que las han marginado.

\section{REFERENCIAS BIBLIOGRÁFICAS}

Apple, M. W. (1991). Ideología y currículo. Madrid: AKAL.

Balsas, M. S. (2011). Negritud e identidad nacional en los libros escolares argentinos: Del surgimiento del sistema nacional de educación al bicentenario. Estudios Sociológicos, 29(86), pp. 649-686.

Barton, K. (2010). Historia e identidad: el reto de los investigadores pedagógicos. En Metodología de la investigación en Didáctica de las Ciencias Sociales (pp. 1328). Zaragoza: Instituto Fernando el Católico-AUPDCS.

Bourdieu, P. (1981). La reproducción. Barcelona: Laia.

Cassany, D. (2006). Tras las líneas. Barcelona: Anagrama.

Castillo, E. (2011). La letra con raza, entra. Racismo, textos escolares y escritura pedagógica afrocolombiana. Pedagogía y Saberes, 34, pp. 61-73. 
Castillo, E. y Rojas, A. (2007). Multiculturalismo y políticas educativas en Colombia ¿interculturalizar la educación? Revista Educación y Pedagogía, 19(48), pp. 1124.

Fontana, J. (2002). La historia de hombres. Barcelona: Crítica.

Foucault, M. (2001). Defender la sociedad. México: FCE.

Fraser, N. (2008). La justicia social en la era de la política de identidad: redistribución, reconocimiento y participación. Revista de Trabajo, 6(4), pp. 83-99.

Granda, S. (2000). Textos escolares e interculturalidad: la representación de la diversidad cultural ecuatoriana. Tesis de maestría, Programa de Maestría en Estudios Latinoamericanos, Mención en Estudios de la Cultura. Universidad Andina Simón Bolívar, Sede Ecuador.

Hall, S. (1997). Cuestiones de identidad cultural. Buenos Aires: Amorrortu.

Hall, S. (2010). El espectáculo del otro. En E. Restrepo, C. Walsh y V. Vich (Eds.), Stuart Hall Sin Garantías. Trayectorias y problemáticas en estudios culturales (pp. 419-446). Bogotá: Envión Editores.

Marolla Gajardo, J. (2014). ¿Aún son invisibles las mujeres? Análisis de la presencia de la historia de las mujeres en los libros texto de secundaria chilenos. En J. Pagès y A. Santisteban (Eds.), Una Mirada al Pasado y un proyecto de Futuro, investigación e innovación en didáctica de las ciencias sociales (pp. 305-314). Barcelona: UAB servei de publicacions.

Marolla, J. y Pagès, J. (2015). Ellas sí tienen historia. Las representaciones del profesorado chileno de secundaria sobre la enseñanza de la historia de las mujeres. Clío \& Asociados, 21, pp. 223-236.

Marolla Gajardo, J. (2019). La Didáctica de las Ciencias Sociales y el problema de la ausencia de las mujeres y su Historia. Reflexiones en torno a un estudio de casos para transformar las prácticas de enseñanza. Revista Electrónica Educare, 23(1), pp. 1-21.

Mclntosh, P. (2005). Gender Perspectives on Educating for Global Citizenship. En N. Noddings, Educating Citizens for Global Awareness (pp. 22-39). New York: Teachers College Press. 
McLaughlin, M. y DeVoogd, G. (2004). Critical literacy. Enhancing Students. Comprehension of text. USA: Scholastic.

MEN. Ministerio de Educación Nacional. (s. f. b). Serie Lineamientos Curriculares Ciencias Sociales: Cátedra de Estudio Afrocolombianos. Bogotá: MEN.

MEN. Ministerio de Educación Nacional. (s. f.). Serie Lineamientos Curriculares Ciencias Sociales. Bogotá: MEN.

Mena, M. I. (2009). La ilustración de África, los africanos y las africanas en los textos escolares de ciencias sociales. Rasgos para el caso colombiano. En, Seminario Internacional sobre Textos Escolares de Historia y Ciencias Sociales. Santiago de Chile, noviembre de 2008. Ministerio de Educación de Chile.

MINEDUC. (2013a). Programa de estudio 1o Básico de Historia, Geografía y Ciencias Sociales. Santiago: Gobierno de Chile.

MINEDUC. (2013b). Programa de estudio 2o Básico de Historia, Geografía y Ciencias Sociales. Santiago: Gobierno de Chile.

MINEDUC. (2013c). Programa de estudio 5o Básico de Historia, Geografía y Ciencias Sociales. Santiago: Gobierno de Chile.

MINEDUC. (2016). Programa de estudio 7o Básico de Historia, Geografía y Ciencias Sociales. Santiago: Gobierno de Chile.

MINEDUC. (2018). Bases Curriculares 1ำ a 6 Básico, Santiago: Gobierno de Chile.

Miralles, P. y Gómez, C. (2017). Enseñanza de la historia, análisis de libros de texto y construcción de identidades colectivas, Historia y Memoria de la Educación, 6, 9-28.

NAP. Núcleos de Aprendizaje Prioritarios. (2018a). Nivel Inicial, Argentina: Ministerio de Educación de Argentina.

NAP. Núcleos de Aprendizaje Prioritarios. (2018b). Nivel Inicial, Segundo año. Argentina: Ministerio de Educación de Argentina.

NAP. Núcleos de Aprendizaje Prioritarios. (2018c). Nivel Inicial, Formación Ética y Ciudadana. Segundo año. Argentina: Ministerio de Educación de Argentina. 
NAP. Núcleos de Aprendizaje Prioritarios. (2018d). Nivel Primaria, Ciencias Sociales. Argentina: Ministerio de Educación de Argentina.

NAP. Núcleos de Aprendizaje Prioritarios. (2018e). Educación Primaria, Segundo ciclo, Ciencias Sociales. Argentina: Ministerio de Educación de Argentina.

NAP. Núcleos de Aprendizaje Prioritarios. (2018f). Educación Secundaria, Ciclo Básico, Ciencias Sociales. Argentina: Ministerio de Educación de Argentina.

NAP. Núcleos de Aprendizaje Prioritarios. (2018g). Educación Secundaria, Ciclo Básico, Formación Ética y Ciudadana. Argentina: Ministerio de Educación de Argentina.

Ortega, D. y Pagès, J. (2017). Literacidad crítica, invisibilidad social y género en la formación del profesorado de Educación Primaria. REIDICS, Revista de Investigación en Didáctica de las Ciencias Sociales, 1, pp. 102-117.

Quijano, A. (2000). Colonialidad del poder, eurocentrismo y América Latina. En E. Lander, (Ed), La colonialidad del saber: eurocentrismo y ciencias sociales. Perspectivas latinoamericanas (pp. 201-245). Buenos Aires, FLACSO.

Quijano, A. (2014). Cuestiones y horizontes: de la dependencia histórico-cultural a la colonialidad/descolonialidad del poder. Buenos Aires: Clacso.

Romero, A. (2010). Educación por y para indígenas y afrocolombianos: las tecnologías de la etnoeducación. Revista Internacional de Investigación en Educación, 3(4), pp. 167-182.

Santisteban, A. (2015). La formación del profesorado para hacer visible lo invisible. En A. M. a Hernández Carretero, C. R. García Ruiz y J. L. de la Montaña (Eds.), Una enseñanza de las Ciencias Sociales para el futuro: recursos para trabajar la invisibilidad de personas, lugares y temáticas (pp. 383-393). Cáceres: Universidad de Extremadura. Asociación Universitaria del Profesorado de Didáctica de las Ciencias Sociales.

Soler, S. (2008). Pensar la relación análisis crítico del discurso y educación. El caso de la representación de indígenas y afrodescendientes en los manuales escolares de Ciencias Sociales en Colombia. Discurso \& Sociedad, 2(3), pp. 642-678.

Spivak, G. (2012). Feminism and Critical Theory. En G. Spivak, In Other Worlds: Essays in Cultural Politics. London: Routledge. 
Tosar, B. (2018). Literacidad crítica y enseñanza de las ciencias sociales en primaria: profe, las bolsas de plástico no son medusas. REIDICIS, Revista de Investigación en Didáctica de las Ciencias Sociales, 2, pp. 4-19.

Tosar, B. y Santisteban, A. (2016). Literacidad critica para una ciudadanía global. Una investigación en Educación Primaria. En C. R. García Ruiz, A. Arroyo y B. Andreu (Eds.), Deconstruir la alteridad desde la didáctica de las ciencias sociales: educar para una ciudadanía global (pp. 674-683). Las Palmas: Universidad de Las Palmas de Gran Canaria-AUPDCS.

Tubino, F. (2005). Entre el multiculturalismo y la interculturalidad: más allá de la discriminación positiva. En N. Fuller (Ed.), Interculturalidad y política: desafíos y posibilidades (pp. 51-76). Lima: RDCSP.

Valle, A. (2009). El trabajo con fuentes y el desarrollo del pensamiento crítico. En Chile, Ministerio de Educación, Seminario Internacional Textos Escolares de Historia y Ciencias Sociales, 2008 (pp. 129-149). Santiago: Ministerio de Educación.

Walsh, C. (2004). Políticas (inter)culturales y gobiernos locales: experiencias ecuatorianas. En, Políticas culturales urbanas: experiencias europeas y americanas. Bogotá: IDCT/Alcaldía Mayor.

Walsh, C. (2006). Interculturalidad y (de)colonialidad: diferencia y nación de otro modo. Pensamiento decolonial: teoría crítica desde América Latina. Buenos Aires: Cátedra Florestan Fernández, Clacso.

Walsh, C. (2011). Etnoeducación e interculturalidad en perspectiva decolonial. Lima: Bellido.

Walsh, C. (2012). Interculturalidad y (de)colonialidad: Perspectivas críticas y políticas, Visao Global, Joaçaba, 15(1-2), pp. 61-74.

Woyshner, C. (2002). Political History as Women's History: Toward a More Inclusive Curriculum. Theory and Research in Social Education, 30(3), pp. 354-380.

Zárate, A. (2010). La lectura crítica en los libros de texto de Educación Secundaria. (Trabajo Fin de Máster). Universidad Pompeu Fabra, Barcelona.

Zárate, A. (2011). Las representaciones sobre los indígenas en los libros de texto de Ciencias Sociales en el Perú. Discurso \& Sociedad, 5(2), pp. 333-375. 